\title{
THE BAYESIAN ANTINOMY RESOLVED
}

\author{
Robert SHEARER ${ }^{1}$, William SHEARER ${ }^{2}$ \\ ${ }^{1}$ Seaver College, Pepperdine University, UNITED STATES, \\ ${ }^{2}$ School of Law, Pepperdine University, UNITED STATES \\ Email $^{1}$ : robert.shearer@pepperdine.edu \\ Email $^{2}$ : william.haworth@pepperdine.edu
}

\begin{abstract}
Philosophers have used Bayes' theorem in their arguments both for and against the existence of miracles for nearly three centuries. The use of this probability rule in opposing arguments suggests an antinomy in the literature. We suggest that this paradox is due not to an inherent flaw in the theorem, but rather is the result of the authors' inherent belief systems. We review the literature in this debate, explain the different positions, and resolve the antinomy.
\end{abstract}

Keywords: Miracles; Bayes Theorem; Probability; Existence of God ;

\section{INTRODUCTION}

John Maynard Keynes once stated of Reverend Bayes' famous probability theorem, 'No other formula in the alchemy of logic has exerted more astonishing powers. For it has established the existence of God from the premise of total ignorance; and it has measured with numerical precision the probability that the sun will rise tomorrow'. ${ }^{1}$ Yet the metaphysical and religious application of Bayes' theorem in assessing the probability of the Divine has been an issue of more contention than Keynes' words suggest. The use of Bayes' theorem to prove or disprove miracles (and by extension, God) has resulted in an ongoing argument between philosophers over the last three centuries. Hume ${ }^{2}$, Sobel ${ }^{3,4}$, Owen ${ }^{5}$, and other skeptics have sought to prove that the infinitesimal probability of a miracle's occurrence makes them impossible to rationally utilize as evidence. Babbage ${ }^{6}$, Schlesinger $^{7}$, Otte $^{8}$, Holder $^{9}$, Earman ${ }^{10}$, and other believers have sought situations in which testimony is

\footnotetext{
${ }^{1}$ John Keynes, A Treatise on Probability (London: Macmillan and Company, 1921), 90-91.

2 David Hume, "Enquiries Concerning Human Understanding and Concerning the Principles of Morals," reprinted from 1777 edition, $3^{\text {rd }}$ edition, ed. L. A. Selby-Bigge (Oxford: Clarendon Press, 1975), 114-115. 3 Jordan Sobel, "On the Evidence of Testimony for Miracles: A Bayesian Interpretation of David Hume's Analysis," Philosophical Quarterly 37, (1987): 166-186.

${ }^{4}$ Jordan Sobel, "Hume's Theorem on Testimony Sufficient to Establish a Miracle," Philosophical Quarterly 163, (1991): 229-237.

5 David Owen, "Hume Versus Price on Miracles and Prior Probabilities: Testimony and the Bayesian Calculation," Philosophical Quarterly 147, (1987): 187-202.

${ }^{6}$ Charles Babbage, The Ninth Bridgewater Treatise: A Fragment, $2^{\text {nd }}$ edition (London: John Murray, 1838) 121130 .

${ }^{7}$ George Schlesinger, "Miracle and Probabilities,” Noûs 2, (1987): 219-232.

${ }^{8}$ Richard Otte, “Schlesinger and Miracles," Faith and Philosophy 10, (1993): 93-98.

${ }^{9}$ Rodney Holder, "Hume on Miracles: Bayesian Interpretation, Multiple Testimony, and the Existence of God," Brit. J. Phil. Sci. 49, (1998): 49-65.

${ }^{10}$ John Earman, “Bayes, Hume, Price, and Miracles,” Proceedings of the British Academy 113, (2002): 91-109.
} 
sufficiently reliable to justify belief in miracles. The theorem therefore produces an antinomy, providing strong arguments both for and against belief in the occurrence of miraculous events. We will show that this antinomy arises from a failure to consider all possible dependencies between testimonies and that the theorem provides a necessary but not sufficient condition to prove either argument.

\section{HUME'S ARGUMENT AGAINST MIRACLES}

The method of investigating the rationality of supernatural belief from a conditional probabilistic perspective originated with the English philosopher David Hume. Concerned with separating metaphysical fact from baseless belief, Hume dedicated a portion of his Inquiry Concerning Human Understanding to the study of the relationship between miraculous events, the testimonies concerning them, and the rationality of the subsequent beliefs they foster in humankind. Such an inquiry required a robust and consistent definition of a miracle as semantic variation in the term's use would inevitably lead to a lack of objectivity, which would in turn make room for disagreement over what constitutes sufficient evidence for the Divine. Hume defined a miracle as 'a violation of the laws of nature ...'11 and for the purposes of this paper we shall hold to this definition. Additionally Hume asserted a necessary condition for knowing that one has seen such a divinely imposed event: ' $\ldots$ no testimony is sufficient to establish a miracle, unless the testimony be of such a kind, that its falsehood would be more miraculous, than the fact'. ${ }^{12}$ Hume's argument is fundamentally a probabilistic one. If, after observing an event, the likelihood that the event was miraculous given a testimony does not exceed the likelihood that the event was non-miracle given the same testimony, then the testimony should be regarded as false and the event as nonmiraculous. Hume's logic is sound; he just lacked the proper formulation as Reverend Price published Bayes' conditional probability theorem several years after Hume's Injury.

\section{THE BAYESIAN ARGUMENT AGAINST MIRACLES}

This argument of Hume's is convenient for study because when applied to Bayes' Theorem it allows us to view miraculous events and the testimonies about them in probabilistic terms. We start with the reasonable assumption that if miracles exist, then they are rare. We then define $\mathrm{M}$ as a miraculous event and $\mathrm{T}$ as the testimony that a miraculous event occurred. We are of course interested in calculating the probability that a miracle occurred given a testimony. Applying Bayes theorem to these events yields the following.

$$
P(M \mid T)=\frac{P(T, M)}{P(T)}=\frac{P(T, M)}{P(T, M)+P(T, \sim M)}=\frac{P(T \mid M) P(M)}{P(T \mid M) P(M)+P(T \mid \sim M) P(\sim M)}
$$

It follows by Hume's logic that in the situation where $P(M \mid T)$ exceeds one half, one can rationally justify belief in a miraculous event, and thereby form a foundation for metaphysical belief. While it would seem from Hume's work that he viewed such convincing testimony as impossible, and that he ultimately sought to discredit the rational foundations of religion, this Bayesian interpretation of his work provides us with a mathematical tool for assessing the probability that any event is the product of Divine intervention. Armed with such a tool, it is no surprise that over the centuries several authors have sought to use it to prove and disprove the actions of the Divine. 'Few arguments have excited greater attention,

\footnotetext{
${ }^{11}$ Hume, "Enquiries Concerning Human Understanding and Concerning the Principles of Morals," 93.

${ }^{12}$ Ibid, 91.
} 
and produced more attempts at refutation, than the celebrated one of David Hume, respecting miracles; and it might be added, that more sophistry has been advanced against it, than its author employed in the whole of his writings ${ }^{\prime 13}$. For Hume, and others like him who seek to discredit religion, the conditions for a credible testimony of a miracle appear so steep that the probability of God's existence touches the infinitesimal. Speaking of Hume's personal view Sobel concludes, 'Hume does not give an example of such testimony. He strongly suspected that there never have been actual examples - that "it will be impossible to find such in all the history. From absence of even a fanciful example of such testimony we should, I think, conclude that he found it impossible to imagine one." ${ }^{14}$. Bayes' theorem appears to reinforce the impossibility of finding a testimony so unfalsifiable that its miraculous implications must be true. 'Applying the elementary techniques of probability theory vindicates Hume's view that when we receive a report of a miraculous event then the probability that the event has actually taken place is smaller than the probability that in fact it has not, ... ${ }^{15}$ (Schlesinger 1987: 225). Consider the following example. We assume that miraculous events are rare that reported testimonies are somewhat reliable. An application of Bayes' Theorem yields the following probability.

$$
\begin{aligned}
& P(M)=0.001 \quad P(T \mid M)=0.90 \quad P(T \mid \sim M)=0.20 \\
& P(M \mid T)=\frac{P(T \mid M) P(M)}{P(T \mid M) P(M)+P(T \mid \sim M) P(\sim M)}=\frac{(0.90)(0.001)}{(0.90)(0.001)+(0.20)(0.999)}=0.0045 \\
& P(M \mid T)=0.45 \%
\end{aligned}
$$

The testimony has increased the likelihood that the observed event was miraculous, but falls far short of the established criterion. As Hume thought, the extreme unlikeliness of a miracle supersedes a highly reliable testimony. The question then becomes, 'in what situations then, should we consider a testified event to be miraculous?' Manipulation of Bayes' theorem yields the answer.

$$
\begin{aligned}
& P(M \mid T)=\frac{P(T \mid M) P(M)}{P(T \mid M) P(M)+P(T \mid \sim M) P(\sim M)}=\frac{1}{1+\frac{P(T \mid \sim M) P(\sim M)}{P(T \mid M) P(M)}}=\frac{1}{1+\frac{P(T, \sim M)}{P(T, M)}} \\
& \begin{aligned}
P(M \mid T)>0.5 & \Rightarrow P(T, M)>P(T, \sim M) \\
& \Rightarrow P(T \mid M) P(M)>P(T \mid \sim M) P(\sim M) \\
& \Rightarrow P(T \mid M) \gg P(T \mid \sim M)
\end{aligned}
\end{aligned}
$$

A miraculous event requires a testimony which is far more likely given a miraculous event than given a mundane event. Or as Hume recognized a testimony for which, ' ... its falsehood would be more miraculous (i.e. less likely), than the fact.'

\footnotetext{
${ }^{13}$ Babbage, "The Ninth Bridgewater Treatise: A Fragment," 120.

${ }^{14}$ Sobel, "On the Evidence of Testimony for Miracles: A Bayesian Interpretation of David Hume's Analysis," 187.

${ }^{15}$ Schlesinger, "Miracle and Probabilities," 226.
} 


\section{THE BAYESIAN ARGUMENT FOR MIRACLES}

For those defending the Deist perspective, Bayes' theorem also provides a defense against skeptical reproach. 'The cynicism remains just cynicism unless it is backed by an argument showing that, in principle, the witnesses cannot be minimally reliable and independent when the alleged miracle is ascribed to system of religion, ${ }^{, 16}$. The most powerful rebuttal to the Atheist position comes in the form of multiple testimonies. Babbage first introduced this idea, and when paired with Bayes' theorem the implications seem to support the rational belief in God. With multiple independent witnesses, the number of testimonies eventually overpowers the extreme unlikeliness of the miracle. The probability of a miraculous event and $n$ testimonies is obtained from the product of independent probabilities.

$P\left(T_{n}, T_{n-1}, \ldots, T_{1}, M\right)=P\left(T_{n} \mid M\right) P\left(T_{n-1} \mid M\right) \times \ldots \times P\left(T_{1} \mid M\right) P(M)=P(T \mid M)^{n} P(M)$

The last equality holds only if each conditional event $T_{i} \mid M$ has the same probability. The probability of a miracle, given multiple independent testimonies can then be calculated as follows.

$$
P\left(M \mid T_{n}, T_{n-1}, \ldots, T_{1}\right)=\frac{P(T \mid M)^{n} P(M)}{P(T \mid M)^{n} P(M)+P(T \mid \sim M)^{n} P(\sim M)}=\frac{1}{1+\left(\frac{P(T \mid M)}{P(T \mid \sim M)}\right)^{n} \frac{P(M)}{P(\sim M)}}
$$

If the witnesses are all more reliable than not, then as the number of testimonies increases, the $\left(\frac{P(T \mid M)}{P(T \mid \sim M)}\right)^{n}$ term converges to zero and $P\left(M \mid T_{n}, T_{n-1}, \ldots, T_{1}\right)$ converges to one.

The implications are thus, '... provided we assume that independent witnesses can be found of whose testimony it can be stated that it is more probable that it is true than that it false, we can always assign a number of witnesses which will, according to Hume's argument, prove the truth of a miracle ${ }^{17}$. The multiple, independent witnesses argument has not been without criticism. Kruskal ${ }^{18}$ and others have pointed out that the very existence of independent witnesses to the same miraculous event is suspect. Even Babbage recognized this flaw in his own writings. More nuanced approaches, such as Holder's ${ }^{19}$ and Tucker's ${ }^{20}$ have attempted to resolve the issues with Babbage's argument, but the debate rages on unabated.

\section{THE ANTINOMY RESOLVED}

We suggest that unaccounted for factors allow for such irreconcilably different conclusions from the same basic argument. Further, a simplistic application of Bayes' theorem to Hume's formulations fails to capture the complexity of the involved probabilities. Fortunately, Hume's framework allows for subtle manipulations that can be easily translated into mathematical terms. By changing basic assumptions about the individuals involved with the

\footnotetext{
${ }^{16}$ Earman, "Bayes, Hume, Price, and Miracles," 102.

${ }^{17}$ Babbage, "The Ninth Bridgewater Treatise: A Fragment," 131.

${ }^{18}$ William Kruskal, "Miracles and Statistics: The Casual Assumption of Independence," Journal of the American Statistical Association 83, (1988): 929-940.

${ }^{19}$ Holder, "Hume on Miracles: Bayesian Interpretation, Multiple Testimony, and the Existence of God," 49-65.

${ }^{20}$ Aviezer Tucker, "Miracles, Historical Testimonies, and Probabilities," History and Theory 44, (2005): 373 390 .
} 
sighting of a miracle, it becomes possible to observe the varying probabilities. As seen in the Bayesian argument for miracles, the assumption of independence is a glaring oversimplification of the issue at hand. William Kruskal, former president of the American Statistical Association, chided this kind of mathematical laziness saying:

'... one may well ask why the assumption of independence is so widespread. One answer is ignorance. ... Far more important than simple ignorance, in my opinion, is seductive simplicity. It is so easy to multiply marginal probabilities, formulas simplify, and manipulation is relatively smooth, so the investigator neglects dependence, or hopes that it makes little difference. Sometimes the hope is realized, but more often dependence can make a tremendous difference' (1988: 933).

While considering the testimonies about miracles, simple and elegant mathematics must also be consistent with reality. Humans do not function in isolation; our words and actions influence each other. All human testimony is inherently dependent on other human action. In this context, the probability of a miraculous event and $n$ testimonies is obtained from the product of conditional probabilities.

$P\left(T_{n}, T_{n-1}, \ldots, T_{1}, M\right)=P\left(T_{n}, T_{n-1}, \ldots, T_{1} \mid M\right) \times \ldots \times P\left(T_{1} \mid M\right) P(M)$

If we assume that an individual's perception of an event is influenced by the perception and testimonies of others who also witnessed the event, then the Bayesian approach to yields the following formulation for $n$ testimonies.

$$
\begin{aligned}
P\left(M \mid T_{n}, T_{n-1}, \ldots, T_{1}\right) & =\frac{P\left(T_{n}, T_{n-1}, \ldots, T_{1}, M\right)}{P\left(T_{n}, T_{n-1}, \ldots, T_{1}, M\right)+P\left(T_{n}, T_{n-1}, \ldots, T_{1}, \sim M\right)} \\
& =\frac{P\left(T_{n}, T_{n-1}, \ldots, T_{1} \mid M\right) P(M)}{P\left(T_{n}, T_{n-1}, \ldots, T_{1} \mid M\right) P(M)+P\left(T_{n}, T_{n-1}, \ldots, T_{1} \mid \sim M\right) P(\sim M)} \\
= & \frac{1}{1+\left(\left[\frac{P\left(T_{n} \mid \sim M, T_{n-1}, T_{n-2}, \ldots, T_{1}\right)}{P\left(T_{n} \mid M, T_{n-1}, T_{\left.n-2, \ldots, T_{1}\right)}\right)}\right]\left[\frac{P\left(T_{n-1} \mid \sim M, T_{n-2}, T_{n-3}, \ldots, T_{1}\right)}{P\left(T_{n-1} \mid M, T_{n-2}, T_{n-3}, \ldots . T_{1}\right)}\right] \times \ldots \times\left[\frac{P\left(T_{1} \mid \sim M\right)}{P\left(T_{1} \mid M\right)}\right]\left[\frac{P(\sim M)}{P(M)}\right]\right)}
\end{aligned}
$$

The issue then becomes the nature of the dependencies. How does an earlier testimony affect future testimonies? Consider the case where two individuals observe a possibly miraculous event. If the first person's testimony increases the likelihood that the second person testifies the opposite, then $P\left(T_{2} \mid T_{1}, \sim M\right)>P\left(T_{2} \mid T_{1}, M\right)$. Continuing with our earlier example, we add such a second observer.

$$
\begin{aligned}
& P(M)=0.001 \quad P\left(T_{1} \mid M\right)=0.90 \quad P\left(T_{1} \mid \sim M\right)=0.20 \\
& P\left(T_{2} \mid T_{1}, M\right)=0.30 \quad P\left(T_{2} \mid T_{1}, \sim M\right)=0.70 \\
& P\left(M \mid T_{2}, T_{1}\right)=\frac{1}{1+\left(\left[\frac{P\left(T_{2} \mid T_{1}, M\right)}{P\left(T_{2} \mid T_{1}, M\right)}\right]\left[\frac{P\left(T_{1} \mid \sim M\right)}{P\left(T_{1} \mid M\right)}\right]\left(\frac{P(\sim M)}{P(M)}\right)\right)}=\frac{1}{1+\left[\left(\frac{0.70}{0.30}\right)\left(\frac{0.20}{0.90}\right)\left(\frac{0.999}{0.001}\right)\right]}
\end{aligned}
$$


$P\left(M \mid T_{2}, T_{1}\right)=0.0019=0.19 \%$

As we saw earlier, the first testimony increased the probability of a miraculous event, but now the contrary second testimony has decreased the probability. Given both testimonies, the event appears even more mundane. By further increasing the number of contrarian testimonies it is possible to have the probability converge to zero (assuming the availability of an infinite number of testimonies). If however, the first person's testimony increases the likelihood that the second person testifies in the same manner, then $P\left(T_{2} \mid T_{1}, \sim M\right)<P\left(T_{2} \mid T_{1}, M\right)$. Revisiting our example we find the following.

$$
\begin{aligned}
& P(M)=0.001 \quad P\left(T_{1} \mid M\right)=0.90 \quad P\left(T_{1} \mid \sim M\right)=0.20 \\
& P\left(T_{2} \mid T_{1}, M\right)=0.95 \quad P\left(T_{2} \mid T_{1}, \sim M\right)=0.15
\end{aligned}
$$

$$
P\left(M \mid T_{2}, T_{1}\right)=\frac{1}{1+\left(\left[\frac{P\left(T_{2} \mid \sim M, T_{1}\right)}{P\left(T_{2} \mid M, T_{1}\right)}\right]\left[\frac{P\left(T_{1} \mid \sim M\right)}{P\left(T_{1} \mid M\right)}\right]\left(\frac{P(\sim M)}{P(M)}\right)\right)}=\frac{1}{1+\left[\left(\frac{0.15}{0.95}\right)\left(\frac{0.20}{0.90}\right)\left(\frac{0.999}{0.001}\right)\right]}
$$

$P\left(M \mid T_{2}, T_{1}\right)=0.0277=2.77 \%$

Now both testimonies increase the likelihood of a miraculous event. Again, by further increasing the number of testimonies it is possible, in a manner similar to Babbage's independent testimonies argument, to have the probability converge to one. We therefore conclude that given dependent testimonies, $P\left(M \mid T_{n}, T_{n-1}, \ldots, T_{1}\right)$ can converge to either one or zero. We can envision cases in which both types of dependency exist. It is just as easy to imagine a crowd of Agnostics swayed by a fervent Atheist as it is to imagine a group of Deists influenced by a charismatic priest. 'It is important to point out that we should grant Hume only that it is unreasonable for a non-Deist to accept miracle stories as credible. For a Deist, on the other hand, it is quite rational to pay credence to such stories ${ }^{21}$. Or as Otte noted, 'once we assume God exists the testimony becomes irrelevant to the miracle, ${ }^{22}$.

\section{CONCLUSION}

The antinomy is thus resolved. The conclusion that one reaches in the end regarding miracles depends on the dependencies between the reported testimonies. As such, one can only show that an event may or may not be miraculous. Proof is beyond our reach with Bayes' theorem.

\section{REFERENCES}

[1] Babbage, Charles. The Ninth Bridgewater Treatise: A Fragment $2^{\text {nd }}$ edition. London: John Murray, 1838 .

[2] Earman, John. "Bayes, Hume, Price, and Miracles." Proceedings of the British Academy 113, (2002): 91-109.

[3] Holder, Rodney. "Hume on Miracles: Bayesian Interpretation, Multiple Testimony, and the Existence of God.” Brit. J. Phil. Sci. 49, (1998): 49-65.

[4] Hume, David. "An Enquiry Concerning Human Understanding, Section X, 'Of Miracles'." In Enquiries Concerning Human Understanding and Concerning the Principles of Morals by David Hume,

\footnotetext{
${ }^{21}$ Schlesinger, "Miracle and Probabilities," 226.

22 Otte, "Schlesinger and Miracles," 95.
} 
$3^{\text {rd }}$ edition, edited by L. A. Selby-Bigge, 3rd ed. revised by P. H. Nidditch, Oxford: Clarendon Press, 1975.

[5] Keynes, John. A Treatise on Probability. London: Macmillan and Company, 1921.

[6] Kruskal, William. "Miracles and Statistics: The Casual Assumption of Independence." Journal of the American Statistical Association 83, (1988): 929-940.

[7] Otte, Richard. "Schlesinger and Miracles." Faith and Philosophy 10, (1993): 93-98.

[8] Owen, David. "Hume Versus Price on Miracles and Prior Probabilities: Testimony and the Bayesian Calculation." Philosophical Quarterly 147, (1987): 187-202.

[9] Schlesinger, George. "Miracle and Probabilities." Noûs 2, (1987): 219-232.

[10] Sobel, Jordan. "On the Evidence of Testimony for Miracles: A Bayesian Interpretation of David Hume's Analysis.” Philosophical Quarterly 37, (1987): 166-186.

[11] Sobel, Jordan. "Hume's Theorem on Testimony Sufficient to Establish a Miracle," Philosophical Quarterly 163, (1991): 229-237.

[12] Tucker, Aviezer. "Miracles, Historical Testimonies, and Probabilities." History and Theory 44, (2005): 373-390. 